\title{
SOLUBILIZACIÓN Y DESPOLIMERIZACIÓN DE PECTINAS DURANTE EL ABLANDAMIENTO DE FRUTOS DE PAPAYA
}

\section{PECTIN SOLUBILIZATION AND DEPOLYMERIZATION DURING PAPAYA FRUIT SOFTENING}

\author{
J. Adriana Sañudo Barajas ${ }^{1}$, Jorge Siller Cepeda ${ }^{1}$, Tomás Osuna Enciso ${ }^{1}$, Dolores Muy Rangel ${ }^{1}$, \\ Guadalupe López Álvarez ${ }^{2}$, Juan Alberto Osuna Castro ${ }^{3}$, Carl Greve ${ }^{4}$ y John Labavitch ${ }^{4}$
}

\footnotetext{
${ }^{1}$ Centro de Investigación en Alimentación y Desarrollo, A.C. Unidad Culiacán. Apdo. postal 32-A. 80129, Culiacán, Sinaloa. México. ${ }^{2}$ Instituto Tecnológico de Culiacán. Sinaloa, México. ${ }^{3}$ Facultad de Ciencias Biológicas y Agropecuarias, Universidad de Colima. Tecomán, Colima, México. ${ }^{4}$ Plant Reproductive Biology, University of California. Davis Ca, U.S.A.

*Autor para correspondencia (jsiller@ciad.edu.mx)
}

\section{RESUMEN}

En este estudio se determinaron los principales cambios en la composición de la pared celular y la degradación de pectinas solubles en agua relacionados con el ablandamiento postcosecha de frutos de papaya (Carica papaya L. cv. 'Maradol'). Se estudiaron frutos en estado de madurez 1/2 (50-75 \% de coloración amarillo-naranja en la cáscara), los cuales se retrasaron en la maduración con $300 \mathrm{~nL} \mathrm{L^{-1 }}$ de 1-metilciclopropeno (1-MCP) o se adelantaron con $2.5 \mathrm{~g} \mathrm{~L}^{-1}$ de ácido 2-cloroetil fosfónico (etefón). Posterior a los tratamientos, los frutos se almacenaron en condiciones de simulación de mercadeo $\left(20 \pm 2{ }^{\circ} \mathrm{C}\right.$ y HR $85 \%$ ) durante 6 d. Se evaluaron los cambios en firmeza, composición de la pared celular y despolimerización de las pectinas solubles en agua. La aplicación de 1-MCP inhibió totalmente el ablandamiento de los frutos. Los frutos testigo perdieron $69 \%$ de la firmeza a los $3 \mathrm{~d}$ de almacenamiento y los frutos con etefón perdieron $84 \%$ en el mismo periodo. El ablandamiento en los frutos testigo y etefón se acompañó de la solubilización de ácidos urónicos y azúcares totales de las fracciones CDTA, $\mathrm{Na}_{2} \mathrm{CO}_{3}$, $\mathrm{KOH} 4 \%$ y $\mathrm{KOH} 24 \%$. La despolimerización extensiva de pectinas solubles en agua y la acumulación de oligómeros derivados de pectinas sólo fue detectada en los tratamientos testigo y etefón, lo que muestra una relación con el ablandamiento de los frutos y sugire la posible acción de la poligalacturonasa.

Palabras clave: Carica papaya, 1-MCP, etileno, maduración, ablandamiento, pared celular.

\section{SUMMARY}

The main changes in cell wall composition as well as the degradation of water soluble pectins that correlate with postharvest softening of papaya fruit (Carica papaya L. cv. 'Maradol') were studied. Fruits in the maturity stage of $1 / 2(50-75 \%$ of yellow-orange peel color) were submitted to treatments for delaying or advancing ripening with $300 \mathrm{~nL} \mathrm{~L}^{-1}$ of 1-methylcyclopropene (1-MCP) or $2.5 \mathrm{~g} \mathrm{~L}^{-1}$ of 2chloroethyl phosphonic acid (ethephon), respectively. Treated fruits were stored under simulated marketing conditions $\left(20 \pm 2{ }^{\circ} \mathrm{C}\right.$ and 85 $\% \mathrm{RH}$ ) during $6 \mathrm{~d}$. Firmness, changes in cell wall composition and solubility and depolymerization of water soluble pectins were monitored. Application of 1-MCP inhibited totally softening and maintained fruit firmness. After $3 \mathrm{~d}$ in storage, control fruits presented a loss of $69 \%$ on firmness while ethephon-treated fruits had a loss of $84 \%$ in firmness during the same period. Fruit softening of the con- trol- and ethephon-treated fruits were accompanied of uronic acids and total sugars solubilization from the $\mathrm{CDTA}, \mathrm{Na}_{2} \mathrm{CO}_{3}, \mathrm{KOH} 4 \%$ and $\mathrm{KOH} 24 \%$ fractions. An extensive depolymerization in the water soluble pectins and an accumulation of pectin-derived oligomers were only detected in control and ethephon-treated fruits, which suggests a relationship with fruit softening and a possible link to polygalacturonase action.

Index words: Carica papaya, 1-MCP, ethylene, ripening, softening, cell wall.

\section{INTRODUCCIÓN}

El ablandamiento postcosecha en frutos de papaya ( $\mathrm{Ca}$ rica papaya $\mathrm{L}$.) es el evento de la maduración que más impacta la vida de anaquel de los frutos, debido a que reduce la aceptabilidad del consumidor, restringe el desplazamiento del producto y aumenta la susceptibilidad a enfermedades (Paull et al., 1997; Manrique y Lajolo, 2004). El ablandamiento extensivo de papaya se relaciona con la degradación progresiva de polisacáridos de la pared celular, los cuales son solubilizados y despolimerizados por acción enzimática, como se ha mostrado en frutos de los cultivares 'Solo', 'Sunset' y 'Eksotika' (Lazan et al., 1989; Ali et al., 1998; Paull et al., 1999; Manrique y Lajolo, 2004). Algunas enzimas relacionadas con la degradación de pectinas y hemicelulosas son: poligalacturonasa $(\mathrm{PG})$, pectinmetilesterasa (PME), $\beta$-galactosidasa ( $\beta$-Gal), xiloglucanasa y xilanasa (Paull y Chen, 1983; Thumdee $e t$ al., 2007). Estas enzimas incrementan su actividad durante la maduración y se les considera responsables de la acumulación de pectinas solubles en agua y la disminución de pectinas unidas iónica y covalentemente a la fase fibrilar (Lazan et al., 1995).

El etileno estimula la iniciación y progresión del ablandamiento de frutos (Hiwasa et al., 2003). Algunos 
procesos bioquímicos regulados por el etileno se identificaron con el uso del gas 1-MCP, el cual inhibe la unión de etileno a sus receptores específicos de membrana y evita así la percepción y transducción de señales que siguen al estímulo hormonal (Blankenship y Dole, 2003; Nishiyama et al., 2007). En papaya 'Sunset' la aplicación de $100 \mathrm{~nL}$ $\mathrm{L}^{-1}$ de 1-MCP redujo el ablandamiento de frutos y las actividades de $\beta$-Gal, PME y glucanasa; sin embargo, no se afectó la actividad de PG medida como la liberación de extremos reductores (Thumdee et al., 2007). Estos resultados contrastan lo reportado por Devitt et al. (2006), quienes observaron que el etileno promovió la expresión de PG y $\beta$-Gal, entre otras hidrolasas de la pared celular.

En este estudio se aplicaron 1-MCP y etefón como inhibidor y promotor del ablandamiento de frutos de papaya 'Maradol', respectivamente, y se estudiaron los cambios en solubilización y despolimerización de pectinas, así como la presencia in vivo de oligogalacturónidos indicadores de la acción de PG.

\section{MATERIALES Y MÉTODOS}

\section{Aplicación de tratamientos}

Se cosecharon frutos de papaya 'Maradol' con 50-75\% de desarrollo de color amarillo-naranja en la cáscara, definido como estado de madurez $1 / 2$. Los frutos se obtuvieron en junio del 2006 de un huerto comercial de Tepic, Nayarit, México. Se seleccionaron frutos sanos y de tamaño uniforme, se desinfectaron por inmersión en una solución de Captán a $0.25 \%$ y se dejaron secar a temperatura ambiente. Se dividieron en tres lotes de 30 frutos cada uno, a los que se aplicaron los tratamientos: 1) $300 \mathrm{~nL} \mathrm{~L}^{-1}$ de 1-MCP; 2) $2.5 \mathrm{~g} \mathrm{~L}^{-1}$ de etefón; y 3) testigo, frutos sin tratar.

La aplicación de 1-MCP se hizo en contenedores de acero inoxidable con sello hermético $\left(0.238 \mathrm{~m}^{3}\right)$ y periodo de exposición de $12 \mathrm{~h}$ a $20{ }^{\circ} \mathrm{C}$. El etefón se aplicó por inmersión de los frutos durante $3 \mathrm{~min}$ a $20^{\circ} \mathrm{C}$. Los frutos testigo no recibieron tratamiento alguno. Después de tratados, los frutos se secaron a temperatura ambiente y se almacenaron durante $6 \mathrm{~d}$ en condiciones de simulación de mercadeo $\left(20 \pm 2{ }^{\circ} \mathrm{C}\right.$ y HR $\left.85 \%\right)$.

\section{Firmeza}

La firmeza se determinó al inicio del estudio y a los 3 y $6 \mathrm{~d}$ de almacenamiento, en tres frutos por tratamiento. Se registró la fuerza de oposición a la punción en cuatro puntos de la zona ecuatorial de cada fruto. La firmeza se midió con un penetrómetro digital Chatillón DFGS-100 adaptado a una base automática TCD 200 y provisto con un punzón de $8 \mathrm{~mm}$, el cual se insertó a una velocidad de 5.3 $\mathrm{mm} \mathrm{s}^{-1}$ (Bourne, 1980). Los resultados se reportan en newtons.

\section{Preparación de la fracción insoluble en alcohol (FIA)}

De las mismas zonas en las que se registró la firmeza de tres frutos, se obtuvieron cortes longitudinales, se eliminó la piel, la pulpa se cortó en cubos de $2 \mathrm{~mm}^{3}$ y se mezcló en una sola muestra. Una porción representativa de 100 g se agregó a $250 \mathrm{~mL}$ de etanol y se calentó a ebullición durante 40 min para inactivar las hidrolasas de la pared celular (Rose et al., 1998). La muestra se enfrió y se homogeneizó en un Ultra-Turrax (modelo T25) a 13500 rpm; los sólidos se recuperaron por filtración en GF/A (fibra de vidrio Whatman); el residuo se lavó secuencialmente con $250 \mathrm{~mL}$ de etanol ( $80 \%), 200 \mathrm{~mL}$ de metanolcloroformo (1:1) y $200 \mathrm{~mL}$ de acetona, hasta obtener un polvo de color blanco. El residuo se secó a $30{ }^{\circ} \mathrm{C}$ y posteriormente se redujo el tamaño de partícula a malla 40 con un molino Thomas Scientific (modelo 3383-L10).

\section{Composición de la fracción insoluble en alcohol (FIA)}

Se determinó por triplicado el contenido de ácidos urónicos (AU) con el método simplificado de Ahmed y Labavitch (1977). Se hidrolizaron $2 \mathrm{mg}$ de la fracción insoluble en alcohol (FIA) con $2 \mathrm{~mL}$ de ácido sulfúrico concentrado $\left(\mathrm{H}_{2} \mathrm{SO}_{4}\right)$ y se añadieron $8 \mathrm{~mL}$ de $\mathrm{H}_{2} \mathrm{O}$ destilada. A $200 \mu \mathrm{L}$ del hidrolizado se adicionaron $1.2 \mathrm{~mL}$ de borato de sodio (12.5 mM) en $\mathrm{H}_{2} \mathrm{SO}_{4}$ concentrado y la mezcla se mantuvo por 5 min en baño de agua a $100{ }^{\circ} \mathrm{C}$. La coloración se produjo al añadir $20 \mu \mathrm{L}$ de m-fenil fenol $(0.15 \%)$ en $\mathrm{NaOH}(0.5 \%)$, y la absorbancia se registró a $520 \mathrm{~nm}$ con un espectrofotómetro Cary UV-Vis 1-E (Varian Inc). Se utilizó ácido galacturónico $\left(\operatorname{Sigma}{ }^{\circledR}\right)$ como patrón de calibración. Los azúcares totales (AT) se determinaron por triplicado por el método de antrona (Yemm y Willis, 1954). Se hidrolizaron $3 \mathrm{mg}$ de la FIA con $3 \mathrm{~mL}$ de $\mathrm{H}_{2} \mathrm{SO}_{4}$ (67\%), manteniendo la mezcla en agitación y baño de hielo durante $4 \mathrm{~h}$. A $100 \mu \mathrm{L}$ del hidrolizado se añadieron 400 $\mu \mathrm{L}$ de $\mathrm{H}_{2} \mathrm{O}$ destilada y $1 \mathrm{~mL}$ de antrona $(0.2 \%)$ en $\mathrm{H}_{2} \mathrm{SO}_{4}$ concentrado; se calentó por 10 min en baño de agua a 100 ${ }^{\circ} \mathrm{C}$ y posterior a su enfriamiento se midió la absorbancia a $620 \mathrm{~nm}$ con un espectrofotómetro Cary UV-Vis 1-E (Varian Inc). La concentración se calculó a partir de una curva de calibración con glucosa.

La composición de azúcares neutros se determinó por el método de acetatos de alditol (Albersheim et al., 1967; Blakeney et al., 1983). Dos miligramos de la FIA se hidrolizaron con ácido trifluoroacético $2 \mathrm{~N}\left(1 \mathrm{~h}\right.$ a $\left.121^{\circ} \mathrm{C}\right)$, se hizo una reducción con $\mathrm{NaBH}_{4}$ a $2 \%\left(1 \mathrm{~h}\right.$ a $\left.25^{\circ} \mathrm{C}\right)$ y 
posteriormente una acetilación con anhídrido acético en presencia de 1-metil imidazol (10 min a $\left.25{ }^{\circ} \mathrm{C}\right)$. El producto derivatizado se inyectó en un cromatógrafo de gases (Varian CP-3800) provisto con detector FID $\left(250^{\circ} \mathrm{C}\right)$, una columna capilar DB-23 de $30 \mathrm{~m} \times 0.25 \mathrm{~mm}\left(210{ }^{\circ} \mathrm{C}\right) \mathrm{y}$ helio a flujo constante $\left(3 \mathrm{~mL} \mathrm{~min}^{-1}\right)$ como gas acarreador. Se usó mio-inositol como estándar interno y la concentración de azúcares neutros se calculó a partir de curvas de calibración de ramnosa, fucosa, arabinosa, xilosa, manosa, galactosa y glucosa (Sigma ${ }^{\circledR}$ ).El residuo de la hidrólisis con ácido trifluoroacético se consideró como celulosa y se determinó en base glucosa por el método de Yemm y Willis (1954).

\section{Solubilidad de la pared celular}

Se extrajeron por duplicado las fracciones solubles en $\mathrm{H}_{2} \mathrm{O}, \mathrm{CDTA}, \mathrm{Na}_{2} \mathrm{CO}_{3}, \mathrm{KOH} 4 \%$ y $\mathrm{KOH} 24 \%$, según el método de Rose et al. (1998). A $200 \mathrm{mg}$ de la FIA se agregaron $25 \mathrm{~mL}$ de $\mathrm{H}_{2} \mathrm{O}$ destilada y la mezcla se agitó por $12 \mathrm{~h}$; se separó la fracción acuosa por centrifugación 6000 $g$. Se hizo una segunda extracción con $20 \mathrm{~mL}$ de $\mathrm{H}_{2} \mathrm{O}$, el sobrenadante se mezcló con el primero y se filtró con GF/A. Con el mismo procedimiento, el sedimento insoluble se extrajo secuencialmente con solución CDTA (50 $\mathrm{mM}$ ) en acetato de sodio ( $50 \mathrm{mM}, \mathrm{pH}$ 6.5), $\mathrm{Na}_{2} \mathrm{CO}_{3}(50$ $\mathrm{mM})$ en $\mathrm{NaBH}_{4}(20 \mathrm{mM}), \mathrm{KOH}(4 \%)$ en $\mathrm{NaBH}_{4}(0.1 \%)$ y KOH (24 \%) en $\mathrm{NaBH}_{4}(0.1 \%)$. Se cuantificó por triplicado el contenido de AU (Ahmed y Labavitch, 1977) y de AT (Yemm y Willis, 1954).

\section{Despolimerización de las pectinas solubles en agua}

Se determinó por cromatografía de exclusión molecular con la metodología de Rose et al (1998) con algunas modificaciones. Se inyectó $1 \mathrm{~mL}$ de la fracción acuosa en una columna Sepharose CL-6B (1.5 x $90 \mathrm{~cm}$, AmershamBiosciences), calibrada con dextranos de peso molecular conocido $(2000,500,150,70$ y $10 \mathrm{kDa})$. La muestra se eluyó con acetato de amonio (50 mM, pH 5.2), a flujo de $30 \mathrm{~mL} \mathrm{~h}^{-1}$. Se obtuvieron fracciones de $1.4 \mathrm{~mL}$ con un colector Bio-Rad (modelo 2110), y a partir de los $38 \mathrm{~mL}$ (volumen muerto) y hasta los $110 \mathrm{~mL}$ (volumen total de elución) se cuantificaron los AU y se reportó la absorbancia a $520 \mathrm{~nm}$ medida con un espectrofotómetro Cary UV-Vis 1E (Varian Inc).

\section{Extracción y análisis de oligómeros derivados de pectinas (ODPs)}

A $80 \mathrm{mg}$ de la FIA se agregaron $10 \mathrm{~mL}$ de $\mathrm{H}_{2} \mathrm{O}$ destilada y se agitó durante $6 \mathrm{~h}$, se filtró en GF/A y se hizo una segunda extracción con $5 \mathrm{~mL}$ de $\mathrm{H}_{2} \mathrm{O}$, de la que se obtuvo la fracción soluble en $\mathrm{H}_{2} \mathrm{O}$. Los oligómeros disueltos se concentraron mediante liofilización y se resuspendieron en $2 \mathrm{~mL}$ del amortiguador de corrida. Se aplicó $1 \mathrm{~mL}$ a una columna Bio-Gel P-4 (1 x 20 cm, Bio-Rad), se eluyó con acetato de amonio $(0.2 \mathrm{M}, \mathrm{pH} 5.2)$ a un flujo de $28 \mathrm{~mL} \mathrm{~h}^{-1}$ y se obtuvieron fracciones de $1.1 \mathrm{~mL}$. El volumen colectado de la fracción 20 a la 40 se mezcló, liofilizó y resuspendió en $500 \mu \mathrm{L}$ de $\mathrm{H}_{2} \mathrm{O}$ grado HPLC del cual $100 \mu \mathrm{L}$ se inyectaron en un HPLC (Dionex) provisto con una columna Carbopac PA-1 (4 x $250 \quad \mathrm{~mm}$, etilvinilbenceno/divinilbenceno y amina cuaternaria) y de un detector de pulso amperométrico. Se utilizó $\mathrm{NaOH} 100 \mathrm{mM}$ y acetato de sodio (gradiente de $400-900 \mathrm{mM}$ ) como eluyente con un flujo de $0.8 \mathrm{~mL} \mathrm{~min}{ }^{-1}$ y tiempo de corrida de $45 \mathrm{~min}$ (Melotto et al., 1994). Los picos se integraron con un integrador Chrom-Jet (Spectra Physics). Se utilizó pectina cítrica (Sigma ${ }^{\circledR}$ ) parcialmente hidrolizada como referencia del grado de polimerización de los ODPs.

\section{Análisis estadístico}

Se utilizó un diseño completamente al azar con tres tratamientos (testigo, 1-MCP y etefón). El análisis de varianza se hizo con el paquete estadístico Minitab versión 13.1, y en caso de valores $\mathrm{P} \leq 0.05$ se hizo comparación de medias por la prueba de Tukey $(\alpha=0.05)$.

\section{RESULTADOS Y DISCUSIÓN}

\section{Firmeza y composición de la pared celular}

Los frutos de los tratamientos testigo y etefón se ablandaron rápidamente en los primeros $3 \mathrm{~d}$ de almacenamiento (Figura 1). La firmeza inicial fue de $118 \mathrm{~N}$ y con la aplicación de 1-MCP se registró un efecto de endurecimiento a través del tiempo (140 y $150 \mathrm{~N})$. Del día 0 al 3, los frutos tratados con etefón perdieron la firmeza a una velocidad de $30 \mathrm{~N} \mathrm{~d}^{-1}$ contra $23 \mathrm{~N} \mathrm{~d}^{-1}$ de los frutos testigo, comportamiento que coincidió con la reducción de azúcares totales (AT) y ácidos urónicos (AU) de la fracción insoluble en alcohol (FIA) (Cuadro 1). El contenido de AT en los frutos testigo y etefón a los $6 \mathrm{~d}$ de almacenamiento, fue significativamente menor con respecto al valor inicial, y en los frutos con 1-MCP no se redujo. La aplicación de etefón aumentó $(\mathrm{P} \leq 0.05)$ la pérdida de AU del día 0 al 6 (de 37.5 a $31.1 \%$ ) con respecto a los otros tratamientos; sin embargo, no se detectaron cambios significativos en el contenido de celulosa.

Los azúcares neutros de la FIA en los frutos testigo y etefón mostraron una reducción de galactosa y ramnosa, y en menor grado de arabinosa, xilosa y manosa; la reducción mayor fue de galactosa (de 3.37 a $2.03 \%$ ) y ramnosa (de 1.53 a $0.93 \%$ ) en los frutos tratados con etefón (Cuadro 2). En los frutos tratados con 1-MCP se observó un 
ligero incremento en todos los azúcares neutros de la FIA, con la excepción de manosa.

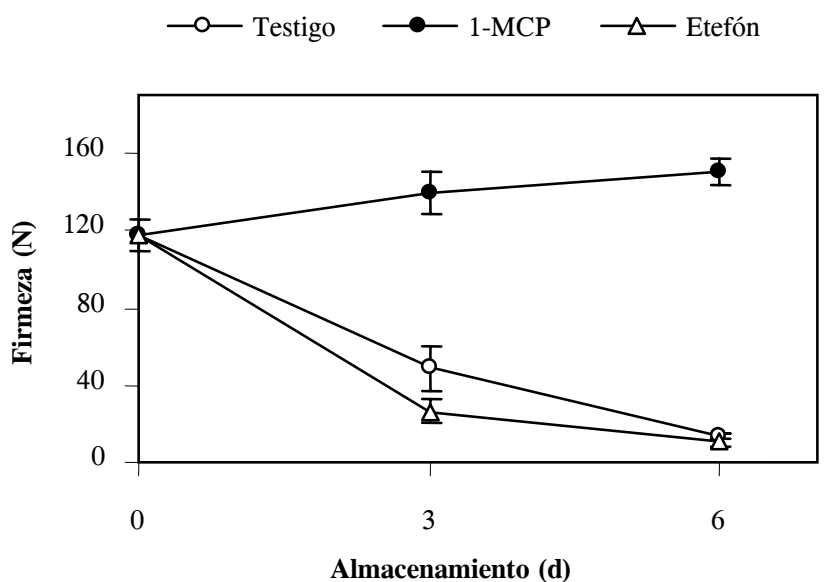

Figura 1. Cambios en la firmeza de frutos de papaya 'Maradol' durante el almacenamiento a $20{ }^{\circ} \mathrm{C}$. Cada punto representa la media \pm error estándar $(\mathbf{n}=3)$.

Cuadro 1. Cambios en el contenido de azúcares totales (AT), ácidos urónicos (AU) y celulosa de la fracción alcohol insoluble en frutos de papaya 'Maradol' almacenados a $20{ }^{\circ} \mathrm{C}$. Los resultados se expresan en por ciento de peso seco.

\begin{tabular}{cccc}
\hline Tratamiento & AT (\%) & AU (\%) & Celulosa $(\%)$ \\
\hline Testigo & $40.42 \mathrm{~b}$ & $37.47 \mathrm{a}$ & $32.16 \mathrm{a}$ \\
Testigo & $35.47 \mathrm{c}$ & $34.89 \mathrm{~b}$ & $32.07 \mathrm{a}$ \\
$1-\mathrm{MCP}$ & $43.87 \mathrm{a}$ & $36.56 \mathrm{ab}$ & $29.04 \mathrm{a}$ \\
Etefón & $35.04 \mathrm{c}$ & $31.05 \mathrm{c}$ & $29.61 \mathrm{a}$
\end{tabular}

Medias con letras diferentes en una columna muestran diferencia estadística (Tukey, 0.05).

\section{Cambios en la solubilidad de la pared celular}

La extracción y solubilización de AU fue más alta en la fracción acuosa (Figura 2A). Después de $6 \mathrm{~d}$ de almacenamiento, los niveles de AU solubles en $\mathrm{H}_{2} \mathrm{O}$ incrementaron en todos los frutos desde $26.4 \%$ al inicio hasta 29.9 , 28.7 y $30.2 \%$ en los frutos testigo y tratados con 1-MCP y etefón, respectivamente. Esta fracción constituyó más de $35 \%$ de la FIA, y los AU en esta fracción superaron por cinco veces a los AT (Figura 2B). El resto de las fracciones también redujeron significativamente su contenido de AU. La fracción CDTA en los frutos con etefón disminuyó en $50 \%$ (de 4 a $2.1 \%$ ), mientras que en los frutos tratados con 1-MCP no hubo cambios $(4.2 \%)$. Las fracciones $\mathrm{Na}_{2} \mathrm{CO}_{3}, \mathrm{KOH} 4 \%$ y KOH $24 \%$ presentaron baja cantidad de AU y mostraron una reducción durante el almacenamiento. Los niveles de AT fueron bajos en todas las fracciones, pero más detectables en las fracciones $\mathrm{H}_{2} \mathrm{O}$ y $\mathrm{KOH} 24 \%$, cuyas proporciones fueron 6.1-7.2 y 3-3.4\%, respectivamente. Los frutos testigo y etefón redujeron significativamente el contenido de AT en las fracciones CDTA y $\mathrm{Na}_{2} \mathrm{CO}_{3}$.

\section{Despolimerización y oligómeros derivados de pectinas (ODPs)}

El perfil cromatográfico de los poliurónidos extraídos en la fracción $\mathrm{H}_{2} \mathrm{O}$, se muestra en la Figura 3. Al día 0 la mayor proporción de poliurónidos eluyó de los 36 a los 70 $\mathrm{mL}$ (2000 a $500 \mathrm{kDa})$; sin embargo, con la maduración y ablandamiento de los frutos los tratamientos testigo y etefón tuvieron un cambio en masa molecular al día 6 , indicado por la acumulación de AU en la región de 60 a 95 $\mathrm{mL}(500$ a $7 \mathrm{kDa})$. Los frutos tratados con 1-MCP redujeron ligeramente al día seis los poliurónidos contenidos en el volumen de elución inicial; sin embargo, la despolimerización fue menos extensiva. La despolimerización de pectinas correlacionó con la presencia y acumulación de ODPs. Al día inicial sólo se observó la presencia de oligómeros acídicos en la región de bajo grado de polimerización y hacia el día seis los frutos testigo y etefón presentaron ODPs con grado de polimerización entre 3 y 7 (Figura 4). En los frutos con 1-MCP hubo baja presencia de oligómeros y picos de baja resolución que no fueron separados con el método empleado, lo que sugiere la presencia de fragmentos complejos que contienen azúcares neutros derivados del metabolismo parcial de pectinas.

Cuadro 2. Cambios en la composición de azúcares neutros de la fracción insoluble en alcohol en frutos de papaya 'Maradol' almacenados a $20{ }^{\circ} \mathrm{C}$. Los resultados se expresan en por ciento de peso seco.

Media \pm desviación estándar $(\mathrm{n}=2)$.

\begin{tabular}{lcccccc}
\hline Tratamiento & Ramnosa & Fucosa & Arabinosa & Xilosa & Manosa & Galactosa \\
\hline Testigo, 0 d & $1.53 \pm 0.05$ & $0.24 \pm 0.01$ & $0.81 \pm 0.01$ & $2.90 \pm 0.03$ & $0.85 \pm 0.03$ & $3.37 \pm 0.04$ \\
Testigo, 6 d & $1.29 \pm 0.31$ & $0.23 \pm 0.05$ & $0.72 \pm 0.14$ & $2.65 \pm 0.54$ & $0.76 \pm 0.20$ & $2.85 \pm 0.83$ \\
1-MCP, 6 d & $1.80 \pm 0.09$ & $0.25 \pm 0.02$ & $0.90 \pm 0.05$ & $3.24 \pm 0.02$ & $0.82 \pm 0.01$ & $3.72 \pm 0.15$ \\
Etefón, 6 d & $0.93 \pm 0.31$ & $0.21 \pm 0.01$ & $0.71 \pm 0.05$ & $2.34 \pm 0.44$ & $0.68 \pm 0.02$ & $2.03 \pm 0.52$ \\
\hline
\end{tabular}



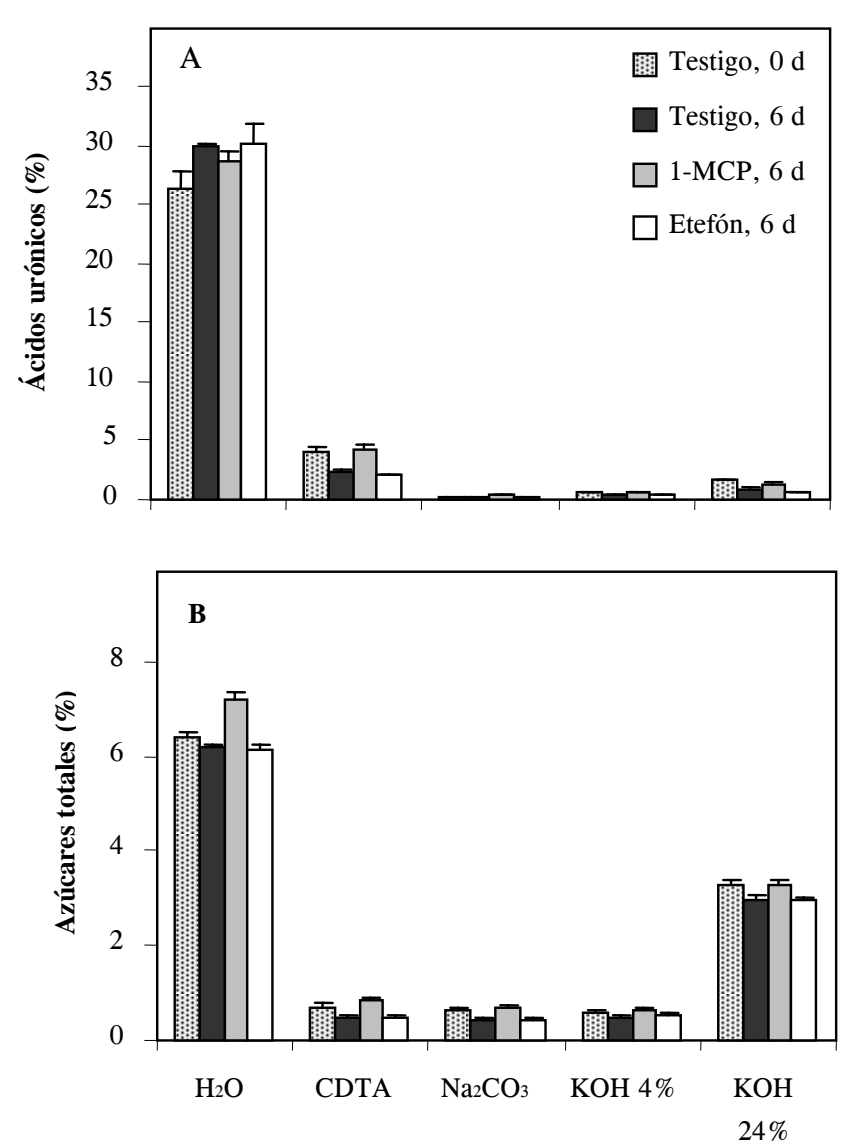

Figura 2. Cambios en solubilidad de las fracciones $\mathrm{H}_{2} \mathrm{O}$, CDTA, $\mathrm{Na}_{2} \mathrm{CO}_{3}$, $\mathrm{KOH} 4 \%$ y KOH $24 \%$ de frutos de papaya 'Maradol' almacenados a $20{ }^{\circ} \mathrm{C}$. A) Ácidos urónicos. B) Azúcares totales. Los resultados se expresan como por ciento en peso de la fracción insoluble en alcohol. Las líneas verticales sobre las barras señalan la desviación estándar $(n=2)$.
El ablandamiento de frutos climatéricos involucra cambios en la estructura de la pared celular. Este proceso, al igual que otros cambios que ocurren en la maduración (color, sabor, olor), se ha definido como un evento regulado por etileno. En los últimos años se ha cuestionado si la regulación del etileno sobre las rutas metabólicas que conducen al ablandamiento de frutos, es total o parcial (Lelièvre, 1997; Nishiyama et al., 2007). En este trabajo, la aplicación de 1-MCP en los frutos de papaya 'Maradol' inhibió totalmente el ablandamiento (Figura 1), diferente a lo reportado en las papayas 'Gold' y 'Rainbow', donde $100 \mathrm{~nL}$ $\mathrm{L}^{-1}$ de 1-MCP causaron un retraso de apenas $30 \%$ en el ablandamiento de frutos con estado de madurez mayor a $25 \%$ (Manenoi et al., 2007). Las diferencias pueden ser debidas a que ellos utilizaron variedades hawaianas con diferente metabolismo y una dosis de 1-MCP menor a la utilizada en el presente estudio. El tratamiento con etefón indujo un ablandamiento acelerado a los frutos al tercer día, mayor al comportamiento normal que presentaron los frutos testigo (Figura 1). También Fabi et al. (2007) reportaron que los frutos de papaya aceleran el ablandamiento con la aplicación de etileno exógeno.

Asociados con el ablandamiento de los frutos se observaron dos eventos predominantes: solubilización de la pared celular y despolimerización de la fracción péctica hidrosoluble (Figuras 2 y 3 ). El tratamiento con 1-MCP inhibió la solubilización y redujo la despolimerización de pectinas, procesos que fueron inducidos con la aplicación de etefón. La reducción de AU y AT en las fracciones CDTA y $\mathrm{Na}_{2} \mathrm{CO}_{3}$ de los frutos testigo y etefón, sugiere la posibilidad de que la despolimerización de pectinas también ocurre a este nivel, como ha sido reportado en las papayas 'Sunset' y 'Eksotika' (Paull et al., 1999; Ali et al., 1998).

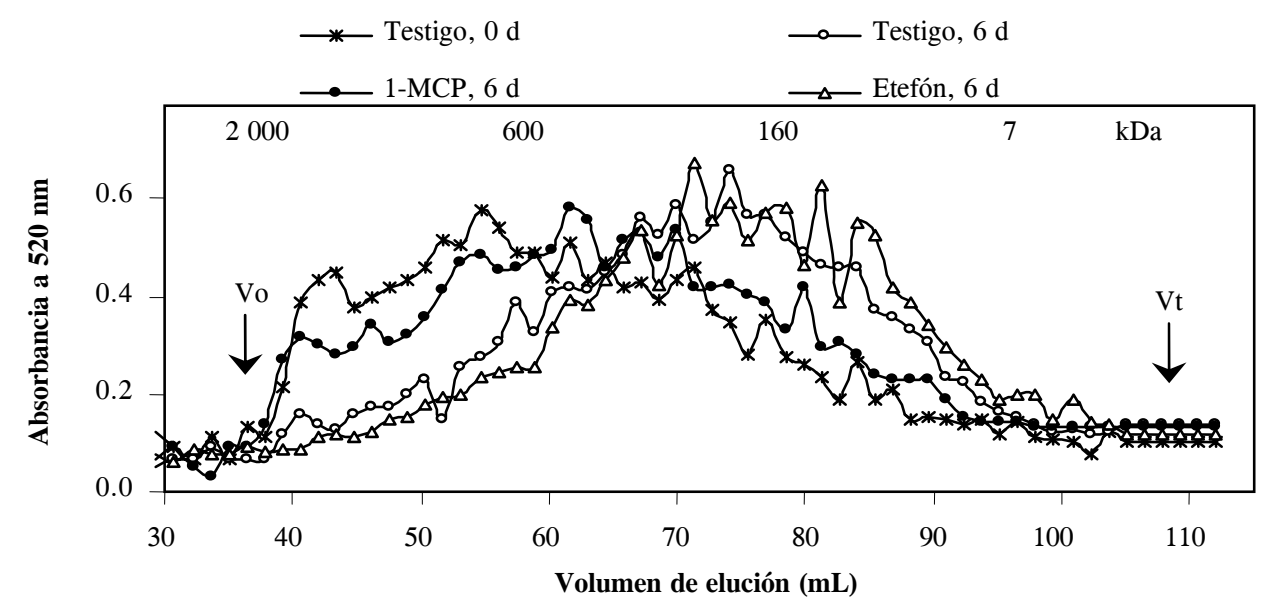

Figura 3. Cambios en la masa molecular de las pectinas solubles en agua de frutos de papaya 'Maradol' almacenados a $20{ }^{\circ} \mathrm{C}$. Exclusión molecular en agarosa CL-6B, las fracciones se analizaron para contenido de ácidos urónicos y se reporta el valor de absorbancia a $520 \mathrm{~nm}$. Vo $=$ volumen muerto; $\mathrm{Vt}=$ volumen total. 
La fracción CDTA está relacionada con la adhesión intercelular y se conforma por pectinas de la región homogalacturonana de la lámina media que se unen iónicamente con la pared celular primaria. La fracción $\mathrm{Na}_{2} \mathrm{CO}_{3}$ está compuesta por polisacáridos con mayor grado de ramificación que entrecruzan la lámina media y la fase microfibrilar por medio de enlaces covalentes (Jarvis et al., 2003). El ablandamiento de los frutos también se relacionó con la solubilización de AU y AT de las fracciones $\mathrm{KOH} 4 \%$ y $24 \%$, lo que indica que ocurre solubilización de hemicelulosas y protopectinas. Este proceso también fue observado en frutos de papaya 'Sunset' y se ha atribuido a la acción de la enzima xilanasa (Paull et al., 1999; Chen y Paull, 2003).

La disminución del tamaño molecular de las pectinas de la fracción acuosa de los frutos testigo y etefón (Figura 3) y la acumulación simultánea de ODPs con bajo grado de polimerización (Figura 4), indican la degradación extensiva de homogalacturonanos. El proceso de despolimerización coincidió con el periodo de mayor ablandamiento de los frutos de papaya, ya que la acumulación de ODPs fue detectada al tercer día de almacenamiento (datos no mostrados). La liberación de oligómeros acídicos puede ser catalizada por la enzima poligalacturonasa (PG), pero es necesario definir la estructura química de los ODPs para descartar la participación de la enzima pectato liasa (Campbell y Labavitch, 1991). Aunque la acción de PG no es un factor determinante en el ablandamiento de frutos como el tomate (Lycopersicon esculentum M.) (Sitrit y Bennett, 1998), contribuye de manera importante en la despolimerización de poliurónidos y en el ablandamiento de frutos de papaya (Paull y Chen, 1983; Paull et al., 1999).

En frutos de melón (Cucumis melo L.), la aplicación de 1-MCP inhibió la producción de endo-PG y retrasó el ablandamiento de los frutos (Nishiyama et al., 2007), tal como pudo ocurrir en el presente estudio. Sin embargo, en papaya 'Sunset' la actividad de PG no correlacionó con el ablandamiento de los frutos y la aplicación de 1-MCP no redujo la actividad de la enzima (Thumdee et al., 2007). Esta variación en los resultados puede estar determinada por la diferencia entre variedades, además de que la actividad de PG fue reportada con base en la liberación de extremos reductores, la cual no discrimina entre actividad exo- y endo-, y es esta última la de mayor impacto en la despolimerización de pectinas.

La reducción de AT en todas las fracciones, que incluye la fracción $\mathrm{H}_{2} \mathrm{O}$, simultáneamente con la pérdida de residuos de azúcares neutros en la FIA, parece indicar que el ablandamiento de frutos de papaya también involucra la acción de enzimas con capacidad de metabolizar polímeros que contienen ramnosa, arabinosa, manosa y principalmente galactosa (Cuadro 2). La pérdida de galactosa ha sido propuesta como un factor de movilización de pectinas enlazadas con las pectinas solubles en agua durante la maduración de frutos (Ranwala et al., 1992; Mwaniki et al., 2005). Rose et al. (1998) reportaron que el contenido de galactosa en las fracciones de pectinas y hemicelulosas extraídas del fruto de melón, disminuyó durante la etapa tardía de la maduración.

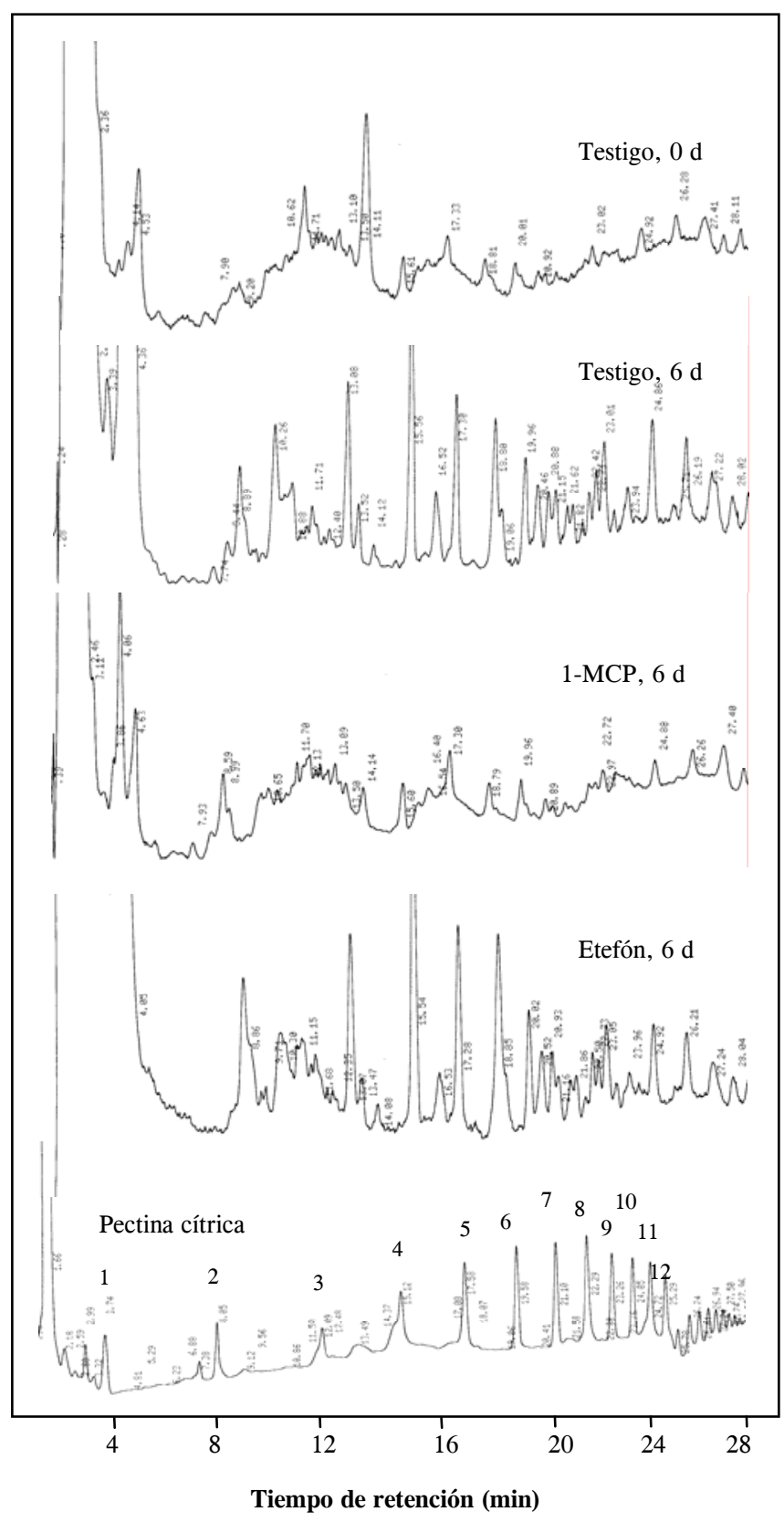

Figura 4. Presencia "in vivo" de oligómeros derivados de pectinas extraídos de frutos de papaya 'Maradol' almacenados a $20^{\circ} \mathrm{C}$. La pectina cítrica parcialmente hidrolizada se utilizó como indicador del grado de polimerización de los oligómeros. 
En frutos de papaya 'Eksotika', Ali et al. (1998) reportaron la participación de $\alpha$ - y $\beta$-Gal durante la maduración e identificaron al menos tres isoformas de $\beta$-Gal con actividad galactanasa ( $\beta$-Gal I, II y III). La actividad de $\beta$-Gal de papaya 'Sunset' se redujo con la aplicación de 1-MCP y se asoció con el retraso del ablandamiento (Thumdee et $a l ., 2007)$. En este estudio la reducción en los residuos de ramnosa y galactosa de la FIA, la pérdida de urónicos y AT de las diferentes fracciones de la pared celular, así como la despolimerización extensiva de poliurónidos solubles en agua a ODPs, sugieren que las enzimas PG y $\beta$ $\mathrm{Gal}$, pueden ser en gran parte responsables de las modificaciones de la pared celular y del ablandamiento de los frutos de papaya 'Maradol'.

\section{CONCLUSIONES}

El ablandamiento postcosecha de frutos de papaya 'Maradol' se asocia con dos eventos predominantes: solubilización de la pared celular y despolimerización de la fracción péctica hidrosoluble. La presencia de oligómeros acídicos potencialmente derivados de la acción de la poligalacturonasa, sugiere su participación en el ablandamiento de los frutos.

\section{AGRADECIMIENTOS}

A UC Mexus-Conacyt por el financiamiento, y a la colaboración técnica de Rosabel Vélez de la Rocha, Laura Contreras Angulo, Rosalba Contreras Martínez y Manuel Báez Sañudo.

\section{BIBLIOGRAFÍA}

Ahmed A E R, J M Labavitch (1977) A simplified method for accurate determination of cell wall uronide content. J. Food Biochem. 1:361-365

Albersheim P, D J Nevins, P D English, A Karr (1967) A method for the analysis of sugars in plant cell-wall polysaccharides by gasliquid chromatography. Carbohyd. Res. 5:340-345.

Ali Z M, S Y Ng, R Othman, L Y Goh, H Lazan (1998) Isolation, characterization and significance of papaya $\beta$-galactanases to cell wall modification and fruit softening during ripening. Physiol. Plant. 104:105-115.

Blakeney A B, P J Harris, R J Henry, B A Stone (1983) A simple and rapid preparation of alditol acetates for monosaccharide analysis. Carbohydrate Res. 113:291-299.

Blankenship S M, J M Dole (2003) 1-Methylcyclopropene: a review. Postharv. Biol. Technol. 28:1-25.

Bourne MC (1980) Texture evaluation of horticultural crops. HortScience 51:51-56.

Campbell A, J M Labavitch (1991) Induction and regulation of ethylene biosynthesis and ripening by pectic oligomers in tomato pericarp discs. Plant Physiol. 97:706-713.

Chen N J, R E Paull (2003) Endoxylanase expressed during papaya fruit ripening: purification, cloning and characterization. Funct. Plant Biol. 30:433-441
Devitt L C, T Sawbridge, T A Holton, K Mitchelson, R G Dietzgen (2006) Discovery of genes associated with fruit ripening in Carica papaya using expressed sequence tags. Plant Sci. 170:356-363.

Fabi J P, B R Cordenunsi, G P de Mattos Barreto, A Z Mercadante, F M Lajolo, J R Oliveira de Nascimento (2007) Papaya fruit ripening: Response to ethylene and 1-methylcyclopropene (1MCP). J. Agric. Food Chem. 55:6118-6123.

Hiwasa K, Y Kinugasa, S Amano, A Hashimoto, R Nakano, A Inaba Y Kubo (2003) Ethylene is required for both the initiation and progression of softening in pear (Pyrus communis L.) fruit. J. Exp. Bot. 53:771-779.

Jarvis M C, S P H Briggs, J P Knox (2003) Intercellular adhesion and cell separation in plants. Plant Cell Environ. 26:977-989.

Lazan H, M K Selamat, Z M Ali (1995) $\beta$-Galactosidase, polygalacturonase and pectinesterase in differential softening and cell wall modification during papaya fruit ripening. Physiol. Plant. 95:106-112.

Lazan H, Z M Ali, K S Liang, K L Yee (1989) Polygalacturonase activity and variation in ripening of papaya fruit with tissue depth and heat treatment. Physiol. Plant. 77:93-98.

Lelièvre J M, A Latché, B Jones, M Bouzayen, J Pech (1997) Ethylene and fruit ripening. Physiol. Plant. 101:727-739.

Manenoi A, E R Bayogan, S Thumdee, R E Paull (2007) Utility of 1methylcyclopropene as a papaya postharvest treatment. Postharv. Biol. Technol. 44:55-62.

Manrique G D, F M Lajolo (2004) Cell-wall polysaccharide modifications during postharvest ripening of papaya fruit (Carica papaya). Postharv. Biol. Technol. 33:11-26.

Melotto E, L C Greve, J M Labavitch (1994) Cell wall metabolism in ripening fruit. Plant Physiol. 106:575-581.

Mwaniki M W, F M Mathooko, M Matsuzaki, K Hiwasa, A Tateishi, K Ushijima, R Nakano, A Inaba, Y Kubo (2005) Expression characteristics of seven members of the $\beta$-galactosidase gene family in 'La France' pear (Pyrus communis L.) fruit during growth and their regulation by 1-methylcyclopropene during postharvest ripening. Postharv. Biol. Technol. 36:253-263.

Nishiyama K, Guis M, J K C Rose, Y Kubo, K A Bennett, L Wangjin, $K$ Kato, $K$ Ushijima, $\mathbf{R}$ Nakano, A Inaba, $M$ Bouzayen, A Latche, J-C Pech, A B Bennett (2007) Ethylene regulation of fruit softening and cell wall disassembly in charentais melon. J. Exp. Bot. 58:1281-1290.

Paull R, N Chen (1983). Postharvest variation in cell wall-degrading enzymes of papaya (Carica papaya L.) during fruit ripening. Plant Physiol. 72:382-385.

Paull R E, K Gross, Y Quiu (1999) Changes in papaya cell walls during fruit ripening. Postharv. Biol. Technol. 16:79-89.

Paull R E, W Nishijima, M Reyes, C Cavaletto (1997) Postharvest handling and losses during marketing of papaya (Carica papaya L.). Postharv. Biol. Technol. 11:165-179.

Ranwala A P, C Suematsu, H Masuda (1992) The role of $\beta$ galactosidases in the modification of cell wall components during muskmelon fruit ripening. Plant Physiol. 100:1318-1325.

Rose J K C, K A Hadfield, J M Labavitch, A B Bennett (1998) Temporal sequence of cell wall disassembly in rapidly ripening melon fruit. Plant Physiol. 117:345-361.

Sitrit Y, A B Bennett (1998) Regulation of tomato fruit polygalacturonase mRNA accumulation by ethylene: a re-examination. Plant Physiol. 116:1145-1150.

Thumdee S, A Manenoi, R E Paull (2007) Activity of papaya fruit hydrolases during natural softening and modified softening. Acta Hort. 740:317-322.

Yemm E W, A J Willis (1954) The estimation of carbohydrates in plant extracts by anthrone. Biochem. J. 57:508-514. 